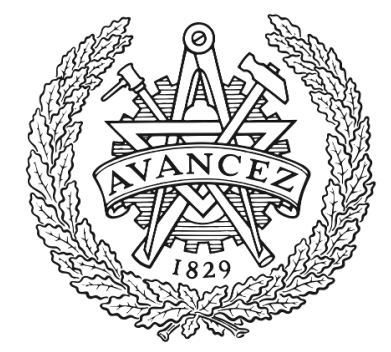

CHALMERS

UNIVERSITY OF TECHNOLOGY

\title{
Intermediate-Level Knowledge in Child-Computer Interaction
}

Downloaded from: https://research.chalmers.se, 2023-04-26 01:19 UTC

Citation for the original published paper (version of record):

Barendregt, W., Eriksson, E., Bekker, T. et al (2018). Intermediate-Level Knowledge in Child-Computer Interaction. Proceedings of the 17th ACM Conference on Interaction Design and Children (IDC '18). http://dx.doi.org/10.1145/3202185.3205865

N.B. When citing this work, cite the original published paper. 


\section{Intermediate-Level Knowledge in Child-Computer Interaction}

\author{
Wolmet Barendregt \\ Eva Eriksson \\ Applied Information Technology, Aarhus University and Chalmers \\ University of Gothenburg \\ 412 96, Gothenburg, Sweden \\ wolmet.barendregt@ait.gu.se \\ Tilde Bekker \\ Industrial Design, Eindhoven \\ University of Technology \\ Eindhoven, The Netherlands \\ m.m.bekker@tue.n \\ Peter Börjesson \\ Computer Science and \\ Engineering \\ Chalmers University of \\ Technology and University of \\ Gothenburg \\ 412 96, Gothenburg, Sweden \\ peter.borjesson@cse.gu.se \\ University of Technology \\ 8200, Aarhus, Denmark \\ evae@cc.au.dk \\ Asimina Vasalou \\ Institute of Education, University \\ College London \\ London, 40222, UK \\ a.vasalou@ucl.ac.uk \\ Olof Torgersson \\ Computer Science and \\ Engineering \\ Chalmers University of \\ Technology and University of \\ Gothenburg \\ 412 96, Gothenburg, Sweden \\ olof.torgersson@cse.gu.se \\ Permission to make digital or hard copies of part or all of this work for personal or \\ classroom use is granted without fee provided that copies are not made or distributed \\ for profit or commercial advantage and that copies bear this notice and the full citation \\ on the first page. Copyrights for third-party components of this work must be honored. \\ For all other uses, contact the Owner/Author. \\ IDC'18, June 19-22, 2018, Trondheim, Norway. \\ (c) 2018 Copyright is held by the owner/author(s). \\ ACM ISBN 978-1-4503-5152-2/18/06. \\ DOI: https://doi.org/10.1145/3202185.3205865
}

\begin{abstract}
In this workshop, we invite researchers to jointly explore how the Child-Computer Interaction (CCl) field can establish intermediate-level knowledge, being a kind of design knowledge that resides in the realm between the design of particular artifacts and theories. In this full day workshop we want to invite (1) researchers and designers who position themselves as producing intermediate-level knowledge (2) people in the field of design research who have not necessarily thought about their work as producing intermediatelevel knowledge. Together we will discuss the pros and cons of different kinds of intermediate-level knowledge and how we can promote the creation of these kinds of knowledge in the $\mathrm{CCl}$ field.
\end{abstract}

\section{Author Keywords \\ Intermediate-level knowledge; $\mathrm{CCl}$.}

\section{CCS Concepts}

- Human-centered computing $\mathrm{HCl}$ theory, concepts and models

\section{Background}

In 2017 several of the organizers of this workshop performed an analysis of all papers at IDC from 2003 to 2016 , showing that 40 percent of those papers presented the design of an artifact accompanied by an evaluation [1]. We will 
refer to such papers as artifact-centered papers. While exploring the design space in the form of artifacts is important and valuable, we argued that those artifact-centered papers generally make a smaller contribution to the field as a whole because it is hard for other designers to build further upon the kind of knowledge presented in such papers. This was also visible in the number of citations to artifact-centered papers in comparison to the number of citations to other kinds of papers.

In the previous paper it was suggested that the $\mathrm{CCl}$ field should try to abstract from the specific examples to generate knowledge that can be re-used across cases, socalled Intermediate-Level Knowledge. According to Höök and Löwgren [4] "In the $\mathrm{HCl}$ field, the dominant approach to knowledge construction is to design innovative interaction schemes and to evaluate them empirically through more or less rigorous use studies". While theories are important input to the design artifact, they are at a level of abstraction that often requires further elaboration in design research.

The idea behind the notion of intermediate-level knowledge is that the space in-between the instances and the theories is non-empty and can be filled with knowledge constructs that are more general than the particular instances but have a different scope and purpose than general level theories (see Figure 1).

We made a first step towards the creation of one particular kind of intermediate-level knowledge, namely strong concepts. According to Höök and Löwgren [4], strong concepts are design elements abstracted beyond particular instances (or artifacts), which have a generative potential, meaning that they can lead to new design ideas and possibilities instead of "focusing, selecting, and combining ideas to form a direction for further detailing, prototyping, or development work" [4]. A strong concept "resides at the interface be-

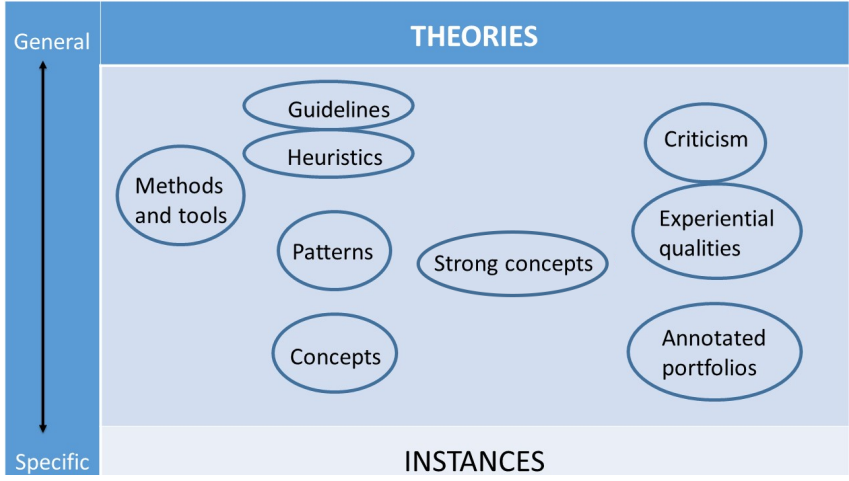

Figure 1: Different forms of Intermediate Level knowledge.

tween technology and people and concerns an artifact's interactive behavior rather than its static appearance. It is a design element, a potential part of an artifact, that also speaks of a use practice and behavior unfolding over time, and it carries a core design idea which has the potential to cut across particular use situations and perhaps even application domains". The construction of strong concepts begins from an instance (or possibly several related instances) by identifying the elements or principles in the instance that could be of value in other design situations within the same genre or domain as the original instance, or transgressing genre/domain boundaries, depending on the abstraction level of the strong concept identified.

In the previous paper, three possible strong concepts were proposed, namely Collective Storytelling, Head-Up Gaming and Remote Sensing. These concepts were based on an analysis of a set of relatively often-cited artifact-centered papers from the IDC conference proceedings. Although the focus in the previous paper was on strong concepts, there are many different forms of intermediate-level knowl- 


\begin{tabular}{|l|l|l|l|l|}
\hline & $\begin{array}{l}\text { Conceptual } \\
\text { constructs }\end{array}$ & $\begin{array}{l}\text { Strong } \\
\text { Concepts }\end{array}$ & $\begin{array}{l}\text { Bridging } \\
\text { concepts }\end{array}$ & $\begin{array}{l}\text { Annotated } \\
\text { portfolios }\end{array}$ \\
\hline $\begin{array}{l}\text { Primary } \\
\text { origins }\end{array}$ & Theory & Instances & $\begin{array}{l}\text { Instances } \\
\text { and theory }\end{array}$ & Instances \\
\hline $\begin{array}{l}\text { Primary } \\
\text { intent }\end{array}$ & $\begin{array}{l}\text { Theoretical } \\
\text { advancements }\end{array}$ & $\begin{array}{l}\text { Informing } \\
\text { design } \\
\text { practice }\end{array}$ & $\begin{array}{l}\text { Facilitating } \\
\text { exchange } \\
\text { between } \\
\text { theory and } \\
\text { practice }\end{array}$ & $\begin{array}{l}\text { Communica } \\
\text { te design } \\
\text { research }\end{array}$ \\
\hline $\begin{array}{l}\text { Construc } \\
\text { tion }\end{array}$ & Top down & Bottom up & $\begin{array}{l}\text { Mediating } \\
\text { between top } \\
\text { and bottom }\end{array}$ & $\begin{array}{l}\text { Design } \\
\text { practice }\end{array}$ \\
\hline Example & Dxnaboek & $\begin{array}{l}\text { Social } \\
\text { navigation }\end{array}$ & Peepholes & $\begin{array}{l}\text { Goldsmith } \\
\text { s } \\
\text { interaction } \\
\text { research } \\
\text { studio }\end{array}$ \\
\hline
\end{tabular}

Figure 2: Comparison of the origins and objectives of different forms of intermediate-level knowledge, inspired by [2].

edge, such as Patterns, Guidelines, Methods and Tools, Bridging Concepts [2], and Annotated Portfolios [3]. Each of these forms serves its own role in design. While guidelines and methods are well-established notions within both $\mathrm{HCl}$ and $\mathrm{CCl}$, other intermediate-level knowledge forms like strong and bridging concepts were introduced rather recently. Our aim with this definition of three strong concepts was to practically demonstrate that $\mathrm{CCl}$ design researchers can contribute to the field with intermediate-level knowledge, and to urge them to do so. We did not claim that strong concepts are the most useful form of intermediatelevel knowledge, nor did we claim that the particular strong concepts we defined were the only possible ones. In this full-day workshop, we would like to build further upon the idea of creating intermediate-level knowledge in the $\mathrm{CCl}$ field going beyond just methods/tools, guidelines, or heuristics. We therefore invite both designers and researchers who position themselves as producing intermediate-level knowledge and people in the field of design research who have not necessarily thought about their work as producing intermediate-level knowledge, to discuss how we can move forward to produce this kind of knowledge.

\section{Scope of the Workshop}

In this workshop we aim to work more broadly on identifying other forms of intermediate-level knowledge going beyond forms that have been previously explored such as guidelines, heuristics, methods and tools. We are especially interested in those forms of intermediate-level knowledge that can potentially have generative power.

\section{Organizers}

Wolmet Barendregt, main contact person, is an Associate Professor at the Department of Applied Information Technology at the University of Gothenburg in Sweden. Her research focuses on user-centered and participatory design of (educational) technologies for children, such as games, reading technologies, and social robots.

Tilde Bekker is an Associate Professor at the Department of Industrial Design at Eindhoven University of Technology in the Netherlands. Her research focuses on user-centered and participatory design of (educational) technologies for children.

Peter Börjesson is a PhD student at the Department of Computer Science and Engineering at Chalmers University of Technology and University of Gothenburg in Sweden. His research focuses on participatory design of collaborative technologies for children in special education. 
Eva Eriksson is an Assistant Professor at the School of Communication and Culture, department of Information Science at Aarhus University in Denmark, and a senior lecturer at Chalmers University of Technology in Sweden. Her research focuses on computational thinking and usercentered and participatory design of technologies for children.

Olof Torgersson is an Associate Professor at the Department of Computer Science and Engineering Chalmers University of Technology and University of Gothenburg in Sweden. His research focuses on user-centered and participatory design of (mobile) technologies for children.

Asimina Vasalou is an Associate Professor at the University College London Institute of Education. She worked in the technology design industry for over ten years before entering academia. Her research sits between the social sciences and interaction design, and examines how digital technologies shape the learning and expression for young people and vulnerable populations. She is also currently a coordinator of the iRead project.

\section{Website}

The workshop website can be found at

http://idac.se/intermediate.

\section{Pre-Workshop Plans}

We invite academic and practitioner submissions interested in the creation of Intermediate Level Knowledge to advance the field of $\mathrm{CCl}$ to participate in this workshop. Submissions should be in the form of a 2-4 page position paper following the SIGCHI Extended Abstracts template ${ }^{1}$. This position paper should either cover an example of the participant's own approach to developing intermediate-level knowledge

\footnotetext{
${ }^{1}$ https://sigchi.org/templates/
}

in the field, or describe a form of intermediate-level knowledge that the participant has identified as particularly useful for their work from a generative perspective. Participants can consider the following questions, broadly or contextualised to their own work:

- What are useful forms of intermediate-level knowledge for the $\mathrm{CCl}$ field?

- What contributions should intermediate-level knowledge make to academia and practice? Where are the overlaps and differences??

- How do we assess the generative power of different forms of intermediate-level knowledge?

- How do we create or extract intermediate-level knowledge in the the $\mathrm{CCl}$ field?

- How could researchers in the CCl field collaborate to produce intermediate-level knowledge?

- How can we make sure that intermediate-level knowledge is applied and updated?

The optimal number of participants is around 15. Selection will be based on the relevance of the position papers with regards to the theme and key issues of the workshop. The selected position papers will be published on the workshop website: http://idac.se/intermediate.

\section{Recruitment Strategy}

The call for participation will be distributed from the end of February to mid April 2018. The workshop coordinators will use their connections with key research centers in $\mathrm{HCl}$ and $\mathrm{CCl}$, to distribute the call for participation. They will be able to reach significant $\mathrm{CCl}, \mathrm{HCl}$ and Design audiences worldwide. The call will also be distributed through key mailing 
lists including $\mathrm{CHI}$ announcement, NordiCHI announcement, Design Research Society, IDC and PD lists. We will also be using social media (Facebook, Twitter) as a means for engaging with potential workshop participants, supplemented by a frequently updated workshop website. The deadline for position papers submissions will be the 15th of April, as indicated by the conference workshop chairs. All submissions will be peer reviewed by the workshop organizers. We plan to host around 15 participants at the workshop, and will therefore aim to accept up to 10 papers. The review and selection process will aim to ensure that the papers address the theme and key issues outlines in the call for papers.

We aim to inform authors of decisions and of any requested changes to their papers approximately two weeks after the submission deadline, on April 31. We will be using the workshop website, along with Twitter, Facebook and email, as a way of frequently updating accepted participants. The workshop website will also be used for all participants to write a blog-post as a preparation for the workshop, ensuring that participants are given the opportunity to familiarize themselves with each other's perspectives on intermediatelevel knowledge before the workshop. Accepted papers will also be published here.

\section{Workshop Structure}

The workshop is planned to last for a full day, with the following schedule:

\section{- (8:00-9:00) Registration desk}

- (9:00-9:15) Welcome and Introduction by organizers

- (9:15-10:00) Five minute presentations by participants about an example of intermediate-level knowledge they have produced, or an example of intermediate- level knowledge that they have found useful for their work

- (10:00-10:15) Coffee break

- (10:15-10:45) Continuation of five minute presentations

- (10:45-12:15) Snowball discussions (going from pairs to groups of four, to groups of eight etc.) around three questions: 1 . What is intermediate-level knowledge? 2. What defines generative power? and 3 . How can we rethink our own design research process and reporting in the light of generative intermediate-level knowledge?

- (12:15-13:30) Lunch (provided by IDC)

- (13:30-15:15) Buzz group discussions where participants are divided into smaller groups. In those groups they discuss the following questions: 1 . How can we produce intermediate-level knowledge within $\mathrm{CCl}$ ? and 2. What are concrete the steps we need to take to make the production of intermediate-level knowledge within $\mathrm{CCI}$ happen? Each groups reports one idea back to the other groups.

- (15:15-15:45) Coffee Break

- (15:45-17:15) Sum up and Future Plans

- $(17: 30)$ Heading towards reception

Accepted participants are asked to write a blog-post on the workshop website describing their position paper. During the workshop they will get the opportunity to present their position orally to all participants. The goal is to point out the direction in knowledge generation in $\mathrm{CCl}$, from several perspectives. 


\section{Post-Workshop Plans}

The expected workshop outcome is a joint proposal for the creation of intermediate-level knowledge in the $\mathrm{CCl}$ field. Based on this proposal we will also define a call for a special issue in an international journal (either IJCCI or IJHCS for which the workshop organizers are editors) where we aim to gather intermediate-level knowledge presently available.

\section{Call for Participation}

In this workshop, we invite researchers to jointly explore how the Child-Computer Interaction (CCI) field can establish intermediate-level knowledge, being a kind of design knowledge that resides in the realm between the design of particular artifacts and theories. In this full day workshop we want to invite (1) researchers and designers who position themselves as producing intermediate-level knowledge (2) people in the field of design research who have not necessarily thought about their work as producing intermediate level knowledge. Together we will discuss the pros and cons of different kinds of intermediate-level knowledge and how we can promote the creation of these kinds of knowledge in the $\mathrm{CCl}$ field.

In order to be admitted to the workshop, the participant should write a 2-4 page position paper following the SIGCHI Extended Abstracts template (https://sigchi.org/templates/). This position paper should either cover an example of the participant's own approach to developing intermediate-level knowledge in the field, or describe a form of intermediatelevel knowledge that the participant has identified as particularly useful for their work from a generative perspective, meaning that it has lead to new design ideas and possibilities.

All submissions should be sent to: evae @ cc.au.dk
Workshop position papers submissions deadline: April 15

Final notification for position papers: April 31

Note that it is a requirement that at least one author of each accepted position paper must attend the workshop and that all participants must register for both the workshop and the main conference.

Website http://idac.se/intermediate.

\section{REFERENCES}

1. Wolmet Barendregt, Olof Torgersson, Eva Eriksson, and Peter Börjesson. 2017. Intermediate-Level Knowledge in Child-Computer Interaction: A Call for Action. In Proceedings of the 2017 Conference on Interaction Design and Children (IDC '17). ACM, New York, NY, USA, 7-16. DOI :

http://dx.doi.org/10.1145/3078072.3079719

2. Peter Dalsgaard and Christian Dindler. 2014. Between Theory and Practice: Bridging Concepts in $\mathrm{HCl}$ Research. In Proceedings of the SIGCHI Conference on Human Factors in Computing Systems (CHI '14). ACM, New York, NY, USA, 1635-1644. DOI : http://dx.doi.org/10.1145/2556288.2557342

3. Bill Gaver and John Bowers. 2012. Annotated portfolios. interactions 19, 4 (2012), 40-49.

4. Kristina Höök and Jonas Löwgren. 2012. Strong Concepts: Intermediate-level Knowledge in Interaction Design Research. ACM Trans. Comput.-Hum. Interact. 19, 3, Article 23 (Oct. 2012), 18 pages. DOI : http://dx.doi.org/10.1145/2362364.2362371 